\title{
Has the Mental Health Act had its day?
}

Unjust discrimination against people with mental ill health should be replaced with universal rules based on decision making ability, writes George Szmukler, but Scott Weich worries about legal distractions that won't improve outcomes while services are so thinly stretched

\section{George Szmukler emeritus professor of psychiatry and society ${ }^{1}$, Scott Weich professor of mental health $^{2}$}

${ }^{1}$ Institute of Psychiatry, Psychology and Neuroscience, King's College, London; ${ }^{2}$ School of Health and Related Research (ScHARR), University of Sheffield

\section{Yes-George Szmukler}

Patients with a "mental disorder" in England and Wales can be detained and treated against their will on legal grounds that are ethically unacceptable. These grounds contribute to the shadow of coercion that hangs over the practice of psychiatry. The relevant law remains fundamentally unchanged since the late 18 th century. ${ }^{1}$

Two sets of rules exist for involuntary treatment-one for psychiatry and one for the rest of medicine. In comparing them, the discrimination against people with a mental illness becomes obvious. $^{23}$

In non-psychiatric cases, the person's ability (or capacity) to make a decision about treatment is key to whether over-riding a refusal can be justified. ${ }^{4}$ A refusal made with capacity is respected no matter what the health outcome might be. Even when capacity is lacking, an involuntary intervention is justified only if it is deemed to be in the person's "best interests." In assessing "best interests" the patient's personal values, beliefs, and commitments have a powerful role. ${ }^{5}$

\section{Capacity and best interests}

These two considerations-capacity and best interests-have almost no role in initiating involuntary treatment in psychiatry. Two entirely different criteria operate: firstly, the presence of a "mental disorder," largely undefined; secondly, a perceived "risk" to the person's health or safety or of harm to others. Thus, autonomy (or the recognition of a right to self determination or to pursue personal goals and values) is not accorded the same respect as among patients with a non-psychiatric diagnosis.

In a pluralistic society such as ours, such attention to values is hugely important. The significant shift in medicine from "paternalism" to patient self determination over the past 50 years has passed psychiatry by. ${ }^{1}$

Furthermore, the protection of other people in the "risk" criterion makes people with mental disorders uniquely liable to a form of preventive detention (albeit usually, or eventually, in hospital) on the basis of risk alone. ${ }^{23}$ They can be detained, unlike the rest of us, without first having committed an offence (or without being strongly suspected of having done so) and despite the fact that only a tiny proportion of violent offenders have a mental illness. ${ }^{6}$

The blurred boundary of what constitutes a "mental disorder" may widen the net for involuntary detention to include some people who are deemed to pose a threat to social order. Justice requires that all people posing an equal risk should be equally liable to preventive detention.

We have accepted such discrimination for so long because of deeply rooted, stigmatising stereotypes of people with mental illness - that is, that they are incapable of exercising judgment and that dangerousness is intrinsic to mental illness. Mental health law is shaped by both assumptions.

The blurred boundary of what constitutes a "mental disorder" may widen the net for involuntary detention to include some people who are deemed to pose a threat to social order

Can we create a legal framework that is non-discriminatory? Indeed we can. ${ }^{37}$ Such a framework is based on decision making ability and best interests but also incorporates the regulation of detention and involuntary treatment with strong human rights protections. Robust assessments, with high agreement between assessors, can be made. ${ }^{8}$ A key point is that the law must be generic: namely, that it applies to everyone who has a problem with decision making, whether the diagnosis is physical or 
psychiatric, and in any setting-medical, surgical, psychiatric, or in the community. A specific "mental health" law is not necessary: the law should be formulated so as to apply throughout all medical specialties, from psychiatry to orthopaedics.

\section{Fusion law can work}

A "fusion law,"3 covering mental health and mental capacity, is an example of such a generic law that Northern Ireland is due to implement in 2018. Fears that such a law will fail to protect the public are unfounded. ${ }^{19}$

The moral case for reforming mental health law is decisive. The discrimination such law entails can no longer be supported. The solution for eliminating this discrimination is a generic law. Northern Ireland has taken the groundbreaking step of enacting such a law ${ }^{10}$; we are sure to see more like it in the future.

\section{No-Scott Weich}

A world without compulsory mental health treatment is a commendable ambition. Psychiatrists are often accused of paternalism and coercion, and we know that compulsory treatment stigmatises patients, causes rifts in social networks, and disrupts therapeutic alliances. Never having to "section" anyone would make our work immeasurably easier. But it would substantially disadvantage those most in need of help.

It is unacceptable that more than 60000 people were subject to the Mental Health Act (MHA) in England last year ${ }^{11}$ and that black patients are three times more likely to be admitted compulsorily than their white counterparts. ${ }^{12}$

The United Nations has said that the United Kingdom, and all signatories to the Convention of the Rights of Persons with Disabilities (CRPD), should repeal legislation authorising compulsory treatment in healthcare. ${ }^{13}$ The UK government has therefore commissioned another costly review of the MHA. Instead of tackling the parlous state of mental health services we're about to embark on further protracted legalistic debate.

What, then, of "fusion" legislation, which argues for compulsory treatment only when decision making capacity is impaired, irrespective of cause? Sadly, it's not CRPD-compliant. Legal minds will be challenged to find a way around the fundamental CRPD principle that disability is a wholly social phenomenon, for which substituted decision making (in the best interests of people incapable of making decisions for themselves) is never permissible. $^{1415}$

Capacity based legislation seems great from a moral perspective: like parity of esteem and personal autonomy, it's impossible to argue against equality under the law for people with physical and mental illnesses.

\section{People in distress would go without help}

So, why don't we abandon the MHA, as in Northern Ireland? Because it won't obviate the need for compulsory treatments-and won't placate the UN as things stand. But, more importantly, lives would be lost, and more people in distress would go without help. It would mean contravening other human rights, including the rights to health, liberty, justice, and life. ${ }^{15}$ The most vulnerable people would probably suffer most.

The MHA allows for compulsory treatment based on evidence of mental disorder plus risk. Restricting this to people judged to lack capacity would inevitably mean some going without treatment, even when it would be in their best interest.
Judgments about mental capacity are notoriously complicated and variable. Assuming (or overestimating) capacity to make life changing decisions poses tremendous risks.

Mental and physical illnesses differ. Mental disorders in general, and several specific conditions such as schizophrenia and mania, commonly lead to impairments in decision making capacity. ${ }^{16}$ Moreover, many patients approve of surrogate treatment retrospectively. ${ }^{17}$

The law is not the problem. Only properly resourced mental health services can reduce rates of compulsion and assure decent, humane outcomes for patients and their families. Because UK services are so thinly stretched, abandoning the MHA would discriminate against people with mental illness by denying them care.

\section{The act ensures that people get help}

One of the paradoxes of the MHA is that its application obliges services to provide care. ${ }^{18}$ Only patients deemed most at risk can access psychiatric beds. In other words, they get help only because the MHA (that is, the law) demands that they get treatment. Consequently, psychiatric wards are more disturbed than ever. The number of patients detained after being admitted voluntarily has increased by more than $15 \%$ per year recently, ${ }^{11}$ and this year record numbers of mental health staff have reported being assaulted.

\section{Psychiatric bed numbers inversely mirror compulsory admission rates, and reductions predict compulsory admission rates in the next year}

The determinants of compulsion in mental healthcare are more social than legal. From 2010 to 2015 NHS mental health budgets fell by an estimated $8.25 \%$, local authority social care budgets fell $13.2 \%$, and over 2000 psychiatric beds were closed. ${ }^{19}$ Psychiatric bed numbers inversely mirror compulsory admission rates, and reductions predict compulsory admission rates in the following year. ${ }^{20}$

And, although black patients are more likely to be assessed and admitted compulsorily than white patients, there is no evidence that ethnicity influences the outcome of MHA assessments. ${ }^{21}$

We can't divorce the law from its setting. Focusing on the MHA is looking too far downstream and is a dangerous distraction. Unless services are properly resourced, changing the law won't make things better for patients, and it might make them very much worse.

The authors are taking part in the 56th Maudsley debate, "This house believes that fundamental reform of the Mental Health Act is required to reduce discrimination and unnecessary detention," on 22 November 2017 at King's College, London.

Competing interests (GS): I have read and understood BMJ policy on declaration of interests and have no relevant interests to declare.

Competing interests: SW is an honorary consultant psychiatrist in Sheffield Health and Social Care Trust, where he is also a university nominated member of the council of governors. He is approved by the secretary of state under S12 of the Mental Health Act and has completed many medical assessments and made medical recommendations for compulsory admission and treatment in this capacity. He currently acts as a responsible clinician for patients subject to community treatment orders. He has undertaken research concerned with uses of the Mental Health Act, funded by the National Institute for Health Research.

Provenance and peer review: Commissioned; externally peer reviewed. 
2 Dawson J, Szmukler G. Fusion of mental health and incapacity legislation. Br J Psychiatry 2006;359:504-9. doi:10.1192/bjp.188.6.504 pmid:16738339.

3 Szmukler G, Daw R, Dawson J. A model law fusing incapacity and mental health legislation. J Mental Health Law 2010;359:11-24.

4 HM Government. Mental Capacity Act 2005. https://www.legislation.gov.uk/ukpga/2005/ 9/pdfs/ukpga_20050009_en.pd.

5 Szmukler G. The UN Convention on the Rights of Persons with Disabilities: "rights, will and preferences" in relation to mental health disabilities. Int J Law and Psychiatry 2017. https://doi.org/10.1016/.jijp.2017.06.003.

6 Flynn S, Rodway C, Appleby L, Shaw J. Serious violence by people with mental illness: national clinical survey. $J$ Interpers Violence 2014;359:1438-58. doi:10.1177/ 0886260513507133 pmid:24309910.

7 Szmukler G, Daw R, Dawson J. A model law fusing incapacity and mental health legislation: outline of the model law. J Mental Health Law 2010;359:101-26.

8 Cairns R, Maddock C, Buchanan A, et al. Reliability of mental capacity assessments in psychiatric in-patients. Br J Psychiatry 2005;359:372-8. doi:10.1192/bjp.187.4.372 pmid: 16199798.

9 Szmukler G, Daw R, Dawson J. A model law fusing incapacity and mental health legislation: response to the commentaries. J Mental Health Law 2010;359:91-100.

10 Northern Ireland Assembly. Mental Capacity Act (Northern Ireland) 2016. www.legislation. gov.uk/nia/2016/18/pdfs/nia_20160018_en.pdf.

11 Community and Mental Health Team. Inpatients formally detained in hospitals under the Mental Health Act 1983, and patients subject to supervised community treatment. Uses of the Mental Health Act: annual statistics, 2015-16. 2016.

12 Weich S, McBride O, Twigg L, et al. Variation in compulsory psychiatric inpatient admission in England: a cross-classified, multilevel analysis. Lancet Psychiatry 2017;359:619-26. doi:10.1016/S2215-0366(17)30207-9 pmid:28647537.

13 United Nations Commission for the Protection of Rights of Persons with Disabilities. Concluding observations on the initial report of the United Kingdom of Great Britain and Northern Ireland (CRPD/C/GBR/CO/1). 2017.
14 Bartlett P. The United Nations Convention on the Rights of Persons with Disabilities and Mental Health Law. Mod Law Rev2012;359:752-78doi:10.1111/j.1468-2230.2012.00923.

15 Freeman MC, Kolappa K, de Almeida JM, et al. Reversing hard won victories in the name of human rights: a critique of the General Comment on Article 12 of the UN Convention on the Rights of Persons with Disabilities. Lancet Psychiatry 2015;359:844-50. doi:10. 1016/S2215-0366(15)00218-7 pmid:26236004.

16 Owen GS, Richardson G, David AS, Szmukler G, Hayward P, Hotopf M. Mental capacity to make decisions on treatment in people admitted to psychiatric hospitals: cross sectional study. BMJ 2008;359:a448. doi:10.1136/bmj.39580.546597.BE pmid:18595931.

17 Owen GS, David AS, Hayward P, Richardson G, Szmukler G, Hotopf M. Retrospective views of psychiatric in-patients regaining mental capacity. Br J Psychiatry 2009;359:403-7. doi:10.1192/bjp.bp.109.065151 pmid:19880929.

18 DeRidder R, Molodynski A, Manning C, McCusker P, Rugkåsa J. Community treatmen orders in the UK 5 years on: a repeat national survey of psychiatrists. BJPsych Bull 2016;359:119-23. doi:10.1192/pb.bp.115.050773 pmid:27280030.

19 Buchanan M. Mental health service budgets "cut by 8\%." BBC News 20 March 2015. www.bbc.co.uk/news/health-31970871.

20 Keown P, Weich S, Bhui KS, Scott J. Association between provision of mental illness beds and rate of involuntary admissions in the NHS in England 1988-2008: ecological study. BMJ 2011;359:d3736. doi:10.1136/bmj.d3736 pmid:21729994.

21 Singh SP, Burns T, Tyrer P, Islam Z, Parsons H, Crawford MJ. Ethnicity as a predictor of detention under the Mental Health Act. Psychol Med 2014;359:997-1004. doi:10.1017/ S003329171300086X pmid:23795603.

Published by the BMJ Publishing Group Limited. For permission to use (where not already granted under a licence) please go to http://group.bmj.com/group/rights-licensing/ permissions 